\title{
Pendidikan Geosista Sebagai Upaya Meminimalkan Penggunaan Gadget pada Anak: Seminar-Workshop untuk Guru dan Orang Tua
}

\author{
Khusnul Khotimah $^{\text {a,1,*, Agus Saputra }}{ }^{\mathrm{b}, 2}$, Baiq Niswatul Khair ${ }^{\mathrm{c}, 3}$, Susi Rahayu ${ }^{\mathrm{d}, 4}$ \\ ${ }^{\mathrm{a}, \mathrm{b}}$ Program Studi Pendidikan Bahasa Inggris, Universitas Mataram. \\ ${ }^{c}$ Program Studi Pendidikan Guru Sekolah Dasar, Universitas Mataram \\ d Program Studi Fisika, Universitas Mataram \\ ${ }^{1}$ khusnul_pena@unram.ac.id* \\ * corresponding author
}

ARTICLE INFO

Article History

Received,19-12-2020

Revised,24-12-2020

Accepted,19-01-2021

Keywords

Geoscience,

Geotourism;

Gadget exposure;

Children education

Rinjani Geopark.

\section{ABSTRACT}

Currently, the use of gadgets has been rampant in all levels of society, including among children. Uncontrolled use of gadgets has more negative impacts, both from social, health, academic and psychosocial aspects. In this regard, the role of parents and teachers is needed to anticipate or reduce the negative impact of using gadgets. However, an understanding of the dangers of gadgets to children and how to prevent or overcome them is not necessarily understood comprehensively by parents and teachers. Seeing these conditions, an innovative activity was carried out which aims to 1) provide an understanding of the dangers of exposure to gadgets and social media in children and 2) socialize and demonstrate the concept of geoscience education and geo-tourism based on geopark as an alternative to reduce gadget exposure to children, as well as enrich practical experiences using the concept of geoscience and geotourism (geosista). This activity is designed for teachers and parents with the hope of being a source of inspiration and also as a guide to be practiced when with children both at school and at home. The concept of GEOSISTA (geoscience and geo-tourism based on Geopark) is considered important for the people of the island of Lombok by considering the potential of a landscape that can provide benefits in both economic, social and cultural aspects. The activities, which are packaged in the form of seminars and workshops, are felt to have an impact on increasing participants' understanding and skills in applying the Geosista concept as an effort to reduce gadget dependence on children. In addition, building a generation that has a strong character in preserving the environment through science can be expected to be a joint mission, both for teachers and parents.

\section{PENDAHULUAN}

Memasuki era rovolusi industri 4.0, akses informasi dan komunikasi semakin luas, mudah, dan cepat. Salah satunya penggunaan gadget sebagai salah satu piranti yang populer saat ini. Popularitas produk teknologi ini tidak hanya sampai pada golongan terpelajar, masyarakat metropolitan, dan usia dewasa saja. Ia juga popular pada seluruh lapisan masyarakat, bahkan juga sampai pada kalangan anak anak (Syahra, 2006).

Anak berusia dibawah 6 tahun merupakan masa emas dan sensitive bagi otak anak (Cahyamaulidiyah, 2014). Masa dimana seluruh aspek diri berkembang pesat dan sangat berperan untuk menopang tahapan perkembangan selanjutnya. Masa ini merupakan fase yang sangat rentan dalam menanggapi fenomena yang ada dilingkungan. Dalam kaitanya dengan penggunaan gadget, anak anak memiliki kerentanan yang berbeda dengan orang dewasa. Saat diberikan gadget, anak anak cenderung menggunakannya untuk bermain game dan menonton film animasi (Ariston \& Frahasini, 2018). Dari kajian beberapa literatur, jika dikomparasikan, penggunaan gadget pada anak lebih banyak membawa dampak buruk daripada dampak positif. Penggunaan gadget pada anak yang tidak terarah memicu timbulnya berbagai masalah diantaranya, masalah kesehatan, 
prestasi dan psikososial (Suhandi, 2013). Secara lebih spesifik, Setianingsih, Ardani, dan Khayati (2018) menemukan bahwa dalam konteks anak usia pra-sekolah, terdapat korelasi antara penggunaan gadget dengan resiko gangguan konsentrasi dan hiperaktivitas. Setelah terpapar gadget anak anak juga terlihat lebih pemals, tidak percaya diri, kurang mampu berkomunikasi dengan baik, menjadi lebih tertutup, dan lebih parahnya akan menjadi kecanduan (Midayana, Darmawani, dan Andriani, 2019). Selain itu, anak yang terpapar gadget juga cenderung memiliki perkembangan sosial yang kurang baik dimana anak cenderung abai terhadap lingkungan dan kurangnya waktu bermain dengan teman temannya (Ariston \& Frahasini, 2018).
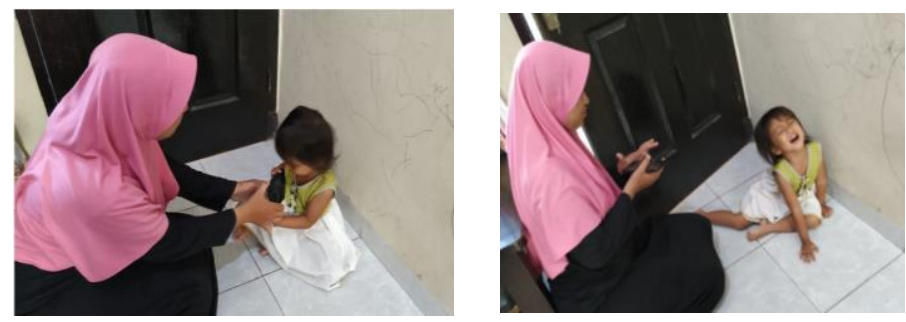

Gambar 1.1. Anak dengan paparan Gadget cenderung tantrum saat dijauhkan dari gadget.

Menanggapi hal ini, banyak kajian yang muncul untuk mencari cara bagimana membantu anak tidak kecanduan dalam menggunakan gadget. Diantaranya adalah Dewi (2020) menemukan bahwa terapi bermain dan penguatan positif (positive reinforcement) terhadap anak dapat mengurangi tingkat intensitas anak dalam menggunakan gadget. Sebelumnya, Ratnaningtyas dan Erwindi (2016) menemukan bahwa penyediaan ruang aktif yang sesuai dengan kebutuhan anak dengan konsep mewadahi kegiatan anak yang produktif dapat membantu mengurangi intensi anak untuk bermain gadget. Secara lebih spesifik Nurfadilah, Zaman, dan Romadona (2019) memberikan catatan pada orangtua untuk mencegah ketergantungan terhadap penggunaan gadget pada anak yaitu:1) Orang tua harus memiliki sikap tegas atau disiplin dengan membatasi waktu penggunaan gadget; 2) Orang tua tidak menggunakan gadget di depan anak; 3) Orangtua memfasilitasi anak untuk bermain di luar rumah dan mengenal tetangga; 4) Orang tua memasukkan ke sekolah agar anak memiliki keterbatasan waktu untuk bermain gadget: dan 5) Orang tua tidak lagi berlangganan wifi di rumah.

Dari literature di atas, dapat disimpulkan bahwa peran orang tua sebagai nyawa pendidikan di ranah keluarga dan guru sebagai agen pendidikan di sekolah sangatlah fundamental. Dua pendidik dewasa ini sangat diperlukan dalam mengarahkan anak-anak agar mampu menggunakan gadget secara bijaksana untuk perkembangan ke arah yang lebih baik. Akan tetapi, gambaran bahaya gadget pada anak ini tidak secara komprehensif dapat dipahami oleh orang tua dan guru. Banyak orang tua dan guru dalam hal ini wali murid dan guru TK se kecamatan Gunung Sari lebih nyaman memberikan gadget pada anak agar anak tidak main di luar, agar anak tidak rewel, atau agar anak tidak kesepian. Mereka kadang merasa kehabisan ide untuk mengisi waktu luang anak, sehingga anak diberi banyak kesempatan untuk bermain dengan gadget. Hal ini tentu akan membawa dampak negatif bagi perkembangan anak seperti: masalah kesehatan, prestasi dan psikososial (Suhandi, 2013), resiko gangguan konsentrasi dan hiperaktivitas (Setianingsih, Ardani, dan Khayati, 2018), terlihat lebih pemals, tidak percaya diri, kurang mampu berkomunikasi dengan baik, menjadi lebih tertutup, dan lebih parahnya akan menjadi kecanduan (Midayana, Darmawani, dan Andriani, 2019), serta cenderung memiliki perkembangan sosial yang kurang baik dimana anak cenderung abai terhadap lingkungan dan kurangnya waktu bermain dengan teman temannya (Ariston \& Frahasini, 2018). Dalam hal ini, ketidakberdayaan orang tua dalam mencegah penggunaaan gadget secara tidak terkontrol banyak disebabkan oleh minimmnya keterampilan orang tua dan guru dalam menciptakan inovasi konsep pendidikan atau alternative kegiatan bagi anak.

Melihat kondisi tersebut, akademisi dalam hal ini dosen di perguruan tinggi wilayah Nusa Tenggara Barat memiliki tanggung jawab moral untuk memberikan pemahaman tentang bahaya gadget pada anak sekaligus menemukan inovasi-inovasi baru terkait konsep pendidikan yang tepat yang bisa digunakan oleh orang tua dan guru dalam membersamai putra putrinya. Salah satunya melalui pendidikan berbasis geopark. Geopark merupakan konsep pembangunan berkelanjutan yang di dukung oleh UNESCO. Kriteria GGN-UNESCO yaitu geopark harus mengkomunikasikan 
pengetahuan geosains dan konsep-konsep lingkungan diantaranya melalui program pendidikan untuk anak-anak (Hardoyo, dkk 2016). Untuk memperdalam konsep-konsep lingkungan ini juga perlu didukung dengan konsep geowisata. Geowisata merupakan kegiatan wisata berbasis alam yang fokus pada kenampakan lekuk permukaan bumi (geologis) untuk mengayakan pemahaman tentang lingungan dan budaya, serta konservasi dan kearifan lokal (Hermawan dkk, 2018). Elemen geosains dan geowisata ini menonjolkan geodiversitas yang beragam. Geodiversitas merupakan komponen tidak hidup yang memiliki manfaat yang sangat besar bagi masyarakat (Henriques, 2017).

Adapun kegiatan yang dilakukan adalah pengenalan konsep pendidikan geosains dan geowisata berbasis geopark pada orang tua dan guru sebagai salah satu alternative yang bisa digunakan untuk mengurangi penggunaan gadget pada anak. Konsep pendidikan geosista atau jika dijabarkan sebagai geosains dan geowisata berbasis geopark ini sangat tepat untuk diperkenalkan secara luas kepada masyarkat Lombok mengingat pulau Lombok ini dikarunia limpahan potensi alam yang manfaat dan keindahannya diakui di tingkat Nasional maupun Internasional. Hal ini dimaksudkan agar sejak dini masyarakat pulau Lombok khususnya di kecamatan Gunungsari sudah diarahkan untuk memiliki pola hidup yang peduli terhadap lingkungan sekitar sehingga mampu memanfaatkan dan menjaga nya secara berimbang.

\section{PELAKSANAAN DAN METODE}

Untuk menyikapi berbagai masalah yang dihadapi mitra, kegiatan pengabdian dipusatkan pada dua kegiatan utama yaitu 1) seminar tentang bahaya gadget; 2) seminar dan workshop tentang konsep pendidikan berbasis geosains dan geowisata. Kegiatan pengabdian kepada masyarakat ini disasarkan bagi orang tua (wali murid) dan guru TK di lingkungan kecamatan Gunung Sari, Kota Mataram, Nusa Tenggara Barat. Kegiatan ini dilakukan pada tanggal 24 agustus 2018 yang dihadihi 38 peserta (20 guru dan 18 wali murid) dengan tiga tahapan yaitu persiapan, pelaksanaan, dan evaluasi.

\section{Persiapan}

Tahap ini lebih pada persiapan materi dan penggalian informasi tentang peserta seminar dan workshop. Tahapan ini dirasa penting untuk dirancang secara matang agar kegiatan dapat berjalan lancar dengan respon yang positif.

\section{Pelaksanaan}

Secara teknis kedua kegiatan ini dilakukan dengan metode ceramah singkat, diskusi, tanyajawab, dan simulasi. Ceramah singkat diberikan ketika menjelaskan tentang teori yang berkaitan dengan materi. Diskusi dan tanya jawab dimaksudkan agar peserta juga ikut berperan aktif dalam menyampaikan permasalahan-permasalahan yang sering di hadapi yang kemudian secara bersama dirumuskan solusi secara cermat. Untuk memberikan gambaran secara jelas tentang aplikasi konsep pendidikan berbasis geosains dan geowisata, peserta mendapatkan sajian simulasi yang bisa diaplikasikan dalam membersamai anak di rumah atau di sekolah.

\section{Evaluasi}

Pada tahap ini akan dilakukan serangkaian proses evaluasi tentang preferensi peserta terhadap kegiatan yang telah dilaksanakan. Tahapan ini menjadi penting sebagai bahan evaluasi bagi penyaji dan sebagai gambaran untuk langkas lanjutan.

Pada kegiatan ini, tim pengusul berkolaborasi dengan Dewan Pelaksana Harian Rinjani Lombok UNESCO Global Geopark (RLUGG), sebuah lembaga bentukan Gubernur Nusa Tenggara Barat yang bertugas untuk koordinasi dan pengelolaan situs-situs Geopark Rinjani yang pada bulan April 2018 ini telah diakui secara resmi sebagai salah satu Geopark Dunia. Salah satu tugas utama Dewan Pelaksana Harian RLUGG adalah mengedukasi masyarakat dalam hal konservasi lingkunan. Berkaitan dengan kegiatanl ini, Dewan Pelaksana Harian RLUGG akan dilibatkan dalam penyampaian materi tentang pentingnya masyarakat Lombok memahami potensi alam pulau Lombok dan cara konservasinya. 


\section{HASIL DAN PEMBAHASAN}

Pelaksanaan kegiatan pengabdian berjalan sesuai rencana, dimana pendampingan dari Manajer Penelitian Pengembangan Pendidikan dan Kebudayaan Geopark Rinjani sangat memberi kontribusi positif. Dalam proses pelaksanaannya, kegiatan ini dibagi menjadi dua sessi besar yaitu seminar dan workshop.

Kegiatan ini dimulai dengan survey dan diskusi singkat dengan peserta. Berdasarkan hasil diskusi dari 38 peserta hanya dua peserta yang tidak membawa smarphone dimana yang satu mengaku tertinggal dan yang satu mengaku tidak memiliki smartphone. Ini artinya bahwa 97,36\% dari peserta dalam hal ini adalah guru dan orang tua menggunakan smartphone dalam keseharian. Adapun 30 peserta (78\%) merespon bahwa anak kecendrungan menangis ketika tidak diberi gadget. Kemudian 24 peserta dari 30 peserta tersebut memberi smartphone pada anak dengan alasan biar cepat diam, bingung bagaimana mengalihkan perhatian, anak-anak bisa bermain permainan edukatif, bisa melakukan pekerjaan lain tanpa diganggu anak. Dari respon tersebut bisa ditarik kesimpulan bahwa peserta yang dalam hal ini adalah orang tua dan guru sebagai pendidik inti bagi anak-anak memiliki pemahaman yang kurang terhadap pola pengenalan gadget yang benar bagi anak. Masih banyak diantara peserta yang menganggap gadget bisa menggantikan perannya dalam membersamai anak. Gadget diposisikan sebagai teman, baby sitter (pengasuh), guru, atau bahkan orang tua.

Di dalam sesi seminar, peserta diberikan muatan pemahaman tentang fenomena penggunaan gatget dan media sosial saat ini dengan stimulasi analisa dampak positif dan negatif dari penggunaannya. Kemudian pembahasan dikerucutkan pada fenomena ketergantungan anak pada gatget, faktor penyebab, ciri-ciri ketergantungan, bahaya yang ditimbulkan, serta cara mengatasinya. Di bagian akhir dari materi seminar, peserta di beri pemaparan tentang kekayaan alam Geopark Rinjani, konsep pendidikan geosains dan geowisata serta urgensinya bagi orang tua dan guru untuk mengenalkan konsep tersebut pada anak. Namun sebelumnya peserta diminta untuk mengisi questionnaire yang menggali pemahaman peserta terkait dengan Geoprak Rinjani dan pentingnya pendidikan berbasis Geopark (geosains dan Geowisata) bagi anak-anak. Questionnaire serupa juga dibagiakan di akhir acara untuk diisi oleh peserta. Hal ini bertujuan untuk mengetahui sejauh mana proses edukasi membawa dampak pada pemahaman peserta.

Kegiatan seminar tersebut dilanjutan dengan kegiatan mini workshop tentang aplikasi konsep pendidikan geosains dan geowisata baik di sekolah atau pun di rumah. Orang tua dan guru diberikan pengalaman untuk mempraktekkan contoh dari pendidikan geosains dan geowisata. Pada tahap ini peserta diberikan pemahan tentang bagaimana mengenalkan gunung Rinjani pada anak, cara peduli pada kelestarian, serta simulasi bagaimana membuat letusan gunung Merapi melalui sains sederhana. Selain itu peserta juga diberi paparan singkat terkait contoh lain sains sederhana yang bisa dipraktekkan bersama siswa atau anak-anak baik di sekolah maupun di rumah.
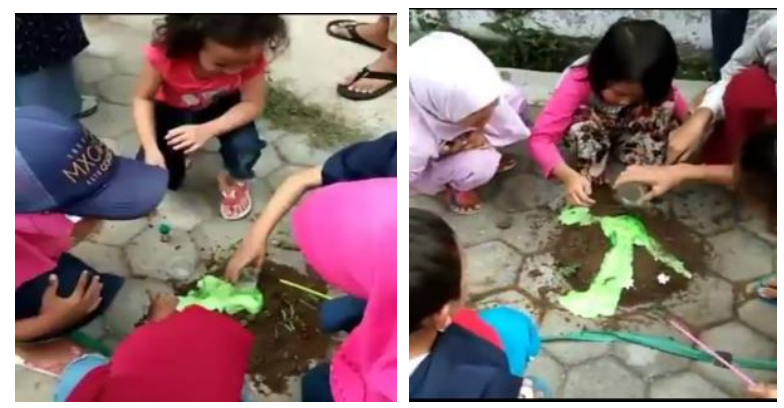

Gambar 2. Aplikasi kegiatan konsep geosista pada anak

Dari hasil observasi dan informal oral feedback, bisa dikatakan bahwa prosesi pengabdian bertajuk pengenalan konsep pendidikan berbasis geosains dan geosiwata untuk mengurangi paparan penggunaan gatget pada anak ini berjalan dengan baik. Terlihat dari sesi diskusi, peserta baik dari guru maupun wali murid sangat antusias untuk bertanya dan berkonsultasi tentang permasalahan yang di hadapi baik tentang upaya pencegahan maupun terapi untuk anak yang terdeteksi kecanduan. Peserta juga merespon dengan positif tentang pengenalan konsep pendidikan geosains dan geowisata. Hal ini terlihat dari keaktifan peserta dalam mengikuti proses simulasi. 
Dari oral feedback bebrapa perwakilan peserta, disampaikan bahwa untuk proses pendidikan di pulau Lombok memang sudah seharusnya mulai mengarah pada pendidikan yang mengaitkan dengan kearifan lokal dalam hal ini mengarah pada menjaga dan memberdayakan kekayaan alam Lombok menggunakan ilmu pengetahuan.

Kegiatan ini berakhir dengan adanya beberapa permintaan untuk mengadakan kegiatan serupa di sekolah-sekolah dengan melibatkan semua guru dan wali murid. Dari kondisi ini bisa disimpulkan bahwa acara ini dapat meningkatkan kesadaran peserta tentang bahaya paparan gatget pada anak dan pentingnya aplikasi dari konsep pendidikan geosains dan geowisata sebagai salah satu alternatif yang baik untuk mengurangi paparan gatget pada anak.

Kegiatan seminar dan mini workshop ini jika dikaji dari detil kegiatan, sangat sesuai dengan temuan penelitian sebelumnya dimana untuk mencegah ketergantungan anak dalam menggunakan gadget orang tua atau guru disarankan untuk dapat memfasilitasi terapi bermain untuk anak (Dewi, 2020), menciptakan ruang aktif kreatif untuk anak (Ratnaningtyas dan Erwindi, 2016), mengenalkan anak dengan lingkunan dan tetangga, serta mengaktifkan fungsi kontrol dalam penggunaan gadget pada anak (Nurfadilah, Zaman, dan Romadona, 2019). Dalam hal ini konsep pendidikan geosista dapat merangkum kebutuhan tersebut dalam satu paket kegitan.

\section{KESIMPULAN}

Penggunaan gatget dan media sosial secara luas dan tak berimbang pada anak tentu membawa dampak buruk. Hal ini harus dicermati oleh semua pihak baik dosen, guru, orang tua, peneliti atau pun masyarakat luas untuk secara bersama menemukan langkah pencegahan, penanganan, dan solusi terbaik. Konsep pendidikan geosains dan geowisata dirasa sangat bagus untuk di gagas di sekolah-sekolah atau rumah-rumah sebagai salah satu jalan alternatif untuk mengurangi jumlah paparan gatget dan media sosial pada anak. Selain itu, bentang alam lengkap dengan segala macam kekayaan yang di miliki oleh pulau Lombok sangat membutuhkan produk pendidikan yang bisa memanfaatkan ilmu pengetahuan untuk menjaga, melestarikan, dan memberdayakan alam secara bijak.

Acara seminar dan worksop yang mengusung kedua tema tersebut dengan sasaran guru dan wali murid ini berjalan lancar dengan respon positif dari peserta. Kegiatan ini diharapkan mampu meningkatkan kesadaran guru dan wali murid untuk lebih peduli terhadap pendidikan terbaik untuk anak. Selain itu juga mampu memberikan gambaran dan pengalam langsung tentang bagaimana mengaplikasikan pendidikan berbasis geosains dan geowisata untuk mengurangi paparan penggunaan gatget dan media sosial pada anak.

\section{UCAPAN TERIMAKASIH}

Ucapan terimakasih kepada Universitas Mataram yang telah memberikan bantuan pendanaan untuk kegiatan pengabdian ini. Sumber dana berasal dari dana DIPA BLU Universitas Mataram nomor 2390/UN18/LPPM/2019.

\section{DAFTAR PUSTAKA}

Ariston, Y. \& Frahasini. Dampak penggunaan gadget bagi perkembangan sosial anak sekolah dasar. Journal of Educational Review and Research, 1(2), 86-91.

Cahyamaulidiyah, Eka. (2014). Anak Usia Dini 6. Di unduh 8 September 2016 dari http://ekacahyamaulidiyah.blogspot.co.id/2014/02/anak-usia-dini_6.html

Dewi, G. A. N.T. (2020). The effectiveness of play therapy and positive reinforcement to reduce gadgets addiction in children: Efektivitas terapi bermain dan positive reinforcement untuk mengurangi kecanduan gadget pada anak. Proceeding of The ICECRS, 8 Educational and Psychological Conference in the 4.0 era articles

Hardoyo Dwi, Muhammad Fuad, dan Taruna Tukiman. (2016). Perencanaan kegiatan wisata pendidikan dalam kawasan Geopark Rinjani Lombok berbasis daya dukung lingkungan (studi daerah Aik Berik). Jurnal Ilmu Lingkungan, 14(2) p 103-107. 
Henriques, Maria H., \& Brilhan Jose. (2017). UNESCO Global Geoparks : Strategy towards global understanding and sustainability. International Union of Geological Sciences Vol.40 No.4.

Hermawan, H., \& Brahmanto, E. (2018, February 26). Geowisata: Pengembangan Pariwisata Berbasis Konservasi. http://doi.org/10.17605/OSF.IO/FMWER

Midayana, Darmawani, E., Andriani, D. (2019). Dampak penggunaan gadget pada anak usia dini (Studi Kasus di TK Elekrina Kertapati Pelmbang). PERNIK Jurnal PAUD, 2(2).

Nurfaidah, F. Zaman, B., \& Romadona, N. F. (2019). Upaya orang tua untuk mencegah ketergantungan anak terhadap penggunaan gadget. EDUKIDS: Jurnal Pertumbuhan, Perkembangan, dan Pendidikan Anak Usia Dini, 16(2), 90-98.

Ratnaningtyas, L. \& Erwindi, C. (2016). Ruang aktif sebagai solusi terhadap pengaruh negatif teknologi pada anak. JURNAL SAINS DAN SENI ITS, 5(2), 2337-3520.

Sismanto. 2011. Geofisika bagian dari geosains dalam eksplorasi sumber daya alam. Prosiding pertemuan ilmiah XXV HFI Jateng \& DIY. ISSN : 0853-0823.

Setianingsih, Ardani, A. W., \& Khayati, F. N. (2018). Dampak penggunaan gadget pada anak usia pra-sekolah dapat meningkatkan resiko gangguan pemusatan perhatian dan hiperaktivitas. GASTER, 26(2), 191-205.

Syahra, R. (2006). Informatika Sosial Peluang dan Tantangan. LIPI. Bandung. 